\title{
Uterine fibroids in pregnancy: prevalence, clinical presentation, associated factors and outcomes at the Limbe and Buea Regional Hospitals, Cameroon: a cross-sectional study
}

\author{
Thomas Obinchemti Egbe ${ }^{1,2^{*}}$ (1) , Therese Gaelle Badjang ${ }^{3}$, Robert Tchounzou ${ }^{4}$, Eta-Nkongho Egbe ${ }^{5}$ \\ and Marcelin Ngowe Ngowe ${ }^{2}$
}

\begin{abstract}
Objectives: Uterine fibroids are common among the black race and associated with adverse outcomes in pregnancy. The aim of this study was to determine the prevalence, clinical presentation and maternal and foetal outcomes of birth among pregnant women with leiomyoma in two secondary care hospitals in Limbe and Buea, Cameroon.

Results: The prevalence of fibroid in pregnancy was 16.7\%. Respondents with leiomyoma were older than those without $(p<0.001)$ and of low parity $(p=0.02)$. Acute abdominal pain, (OR 3.8; $95 \% \mathrm{Cl} 1.4-9.9, p=0.007)$, vaginal bleeding (OR 5.2; $95 \% \mathrm{Cl} 1.6-16.3, p=0.004$ ) were clinical presentation of leiomyoma in pregnancy. Cesarean birth (OR 4.5; 95\% Cl 1.4-13.6, $p=0.008)$, low Apgar score, (OR 6.0; 95\% Cl 1.9-19.1, $p=0.002)$, and postpartum hemorrhage (OR 4.7; 95\% Cl 1.7-13.2, $\mathrm{p}=0.003$ ) were adverse outcomes recorded.
\end{abstract}

Keywords: Uterine fibroid, Pregnancy, Outcome, Cameroon

\section{Introduction}

Uterine fibroids are common amongst black women, have an earlier onset and are usually multiple and with higher complication rates than among white women [1]. The prevalence of uterine fibroids diagnosed by first trimester ultrasound was 18\% in African American women [2] and $12.5 \%$ in Benin [3].

The few studies in Cameroon reported increased adverse obstetric outcomes among pregnant women with fibroids compared with those without [4].

Advances in ultrasonography have led to improved diagnostic criteria for uterine fibroids in pregnancy. In particular, these advances have impacted: (1) operational definitions that require a large diameter to define the presence of uterine fibroids (2) inconsistent documentation of uterine fibroids in clinical data used for research

\footnotetext{
*Correspondence: toegbe@gmail.com; Obinchemti@yahoo.com 2 Faculty of Health Sciences, University of Buea, P.O.Box 63, Buea, Cameroon

Full list of author information is available at the end of the article
}

(3) difficulty detecting uterine fibroids as pregnancy progresses since uterine anatomy, foetus and placenta interfere with complete assessment of the myometrium.

Uterine fibroids are common among antenatal care attendants and parturients at the Limbe and Buea Regional Hospitals (LRH and BRH), Cameroon. However, we are not aware of any study regarding the association between uterine leiomyoma and pregnancy in the South West Region of Cameroon. We aimed at determining the prevalence, clinical presentation and maternal and foetal outcomes of birth among pregnant women with leiomyoma in two secondary care hospitals in Limbe and Buea, Cameroon.

\section{Main text \\ Methods}

\section{Study design and setting}

This was a cross-sectional study of pregnant women attending antenatal care at the Limbe and Buea Regional

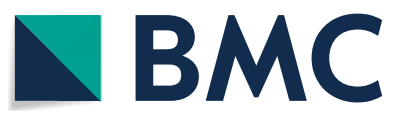

C The Author(s) 2018. This article is distributed under the terms of the Creative Commons Attribution 4.0 International License (http://creativecommons.org/licenses/by/4.0/), which permits unrestricted use, distribution, and reproduction in any medium, provided you give appropriate credit to the original author(s) and the source, provide a link to the Creative Commons license, and indicate if changes were made. The Creative Commons Public Domain Dedication waiver (http://creativecommons.org/ publicdomain/zero/1.0/) applies to the data made available in this article, unless otherwise stated. 
Hospitals in Cameroon during the period 1st April 2013 to 31st December 2013.

The LRH (birth rate of 1200 births per year) and BRH (birth rate 1050 births/year) are two secondary healthcare facilities that serve as referral centres in the South West Region of Cameroon and equipped to provide comprehensive emergency obstetric and neonatal care $(\mathrm{EmONC})[5,6]$.

\section{Data collection and analysis}

With a $95 \%$ confidence interval and power of $80 \%$ and a pre-study estimate of the prevalence of fibroids in pregnancy of $18 \%$ among African-American women [2], we estimated the minimum sample size of 226 participants using the Lorenz formula [7].

Structured questionnaires (approved by the Review Board of the University of Buea) that were pretested (tested on 15 pregnant women 1 week earlier for content validity) were administered to pregnant women aged $\geq 21$ years who signed a written informed consent form, with a viable singleton intrauterine pregnancy and whose antenatal care was at the study health facilities by convenient and consecutive sampling method. The respondents should have a baseline first trimester ultrasound scan with data on uterine fibroids on those having fibroids and were willing to carry pregnancy to term, with no intention of moving from Limbe or Buea over the next 1 year and had to speak English, Pidgin or French. The study was designed to enrol women in the third trimester of pregnancy $\geq 28$ weeks of gestation. During the face-to-face interview, the interviewer gathered information regarding diagnosis and treatment of uterine fibroids prior to current pregnancy and the data was later confirmed by studying the medical records of the respondents. Data regarding: personal and socio-demographic information, past and present obstetric and gynaecologic history were recorded. We also recorded maternal weight, height and blood pressure, fundal height, abdominal circumference including foetal presentation, position and heart rate.

Ultrasonography information of fibroids was based on Muram criteria [8]. The fibroid were identified, their diameter was measured in three perpendicular planes; measurements were made two times and fibroid diameter was averaged and mapped into a uterine diagram. It was later categorised by location (fundus, corpus, isthmus or cervix), position (anterior, posterior, right, left), and type (sub mucous-any fibroid in contact with or distorting the uterine cavity without identifiable myometrium between the fibroids and the endometrium, intramural-within the myometrium, neither distorting the contour nor the cavity, sub serous-distorting the external contour of the uterus, and pedunculated-attached to the uterus with an identifiable stalk). Participants with multiple fibroids had each fibroid documented separately and foetal morphology; placenta and adnexa images were saved initially in still print images and later on digital images on USB and sent for review by study investigators.

Participants were also taught the symptoms and signs of labour and asked to report to the maternity in case of labour.

During labour/delivery, the questionnaire was completely filled: gestational age at delivery, induction/augmentation of labour or not, mode of delivery (vaginal or caesarean), and foetal presentation at delivery were recorded. Maternal blood loss was also recorded.

Parameters of the baby studied were: Apgar score, birth weight, length, head, chest and abdominal circumferences.

At the end of the study, basic post-partum care education was given to all the respondents (advice on breastfeeding, contraception, breast and vulvar hygiene etc.).

The data collected was coded, double entered and analysed using EPI INFO ${ }^{\mathrm{TM}}$ 3.5.1 software. The categorical data (number of fibroids, gravidity, parity, educational level and employment status) were presented as frequencies and percentages whereas continuous variables (age, gestational age, Apgar score, foetal birth weight, body mass index (BMI)) were expressed as means and standard deviations. We compared percentages between two groups using the student $\mathrm{t}$-test and Chi squared test where appropriate and Odds ratios and their 95\% confidence intervals were generated and significance level was set at $\mathrm{p}<0.05$.

\section{Results}

During the study period, we approached 288 pregnant women; 18 (9.27\%) did not consent to study and 44 (22.68\%) were excluded because of lack of first trimester ultrasound scan. We were then left with 226 (68.04\%) respondents who completed the study among which; 38 (16.7\%) had fibroids and 188 (83.3\%) were without fibroids (Additional file 1: Figure S1).

Respondents with uterine fibroid in pregnancy were older than those without $(\mathrm{p}<0.001)$ and majority were in the age group $25-30$ and $30-35$ years $(\mathrm{p}=0.001)$. They were mainly primiparous $(\mathrm{p}=0.02)$ (Table 1$)$.

The mean size of fibroids was $2.82($ SD 1.64) $\mathrm{cm}$ and $41 \%$ respondents had a sensation of pelvic heaviness. Majority, $63.7 \%$ fibroids were sub-serous, $22.7 \%$ were sub-mucous and $13.6 \%$ intramural. About $22.7 \%$ respondents had $\leq 1$ child while $50 \%$ had $2-3$ children (Additional files 2, 3: Figures S2, S3 (Table 2).

Acute abdominal pain, (OR 3.8; 95\% CI 1.4-9.9, $\mathrm{p}=0.007$ ), vaginal bleeding (OR 5.2; 95\% CI 1.6-16.3, $\mathrm{p}=0.004$ ), Cesarean birth (OR 4.5; 95\% CI 1.4-13.6, 
Table 1 General characteristics of participants

\begin{tabular}{|c|c|c|c|c|c|c|c|}
\hline Variable & $\begin{array}{l}\text { Over all } \\
(N=226)\end{array}$ & Percentage \% & $\begin{array}{l}\text { Fibroids } \\
(\mathrm{N}=38)\end{array}$ & Percentage \% & $\begin{array}{l}\text { No fibroids } \\
(\mathrm{N}=188)\end{array}$ & Percentage \% & p-value \\
\hline Age (years), mean (SD) & 28.1 & 4.3 & 31.4 & 3.4 & 27.4 & 4.2 & $<0.001$ \\
\hline \multicolumn{8}{|l|}{ Age (years), n (\%) } \\
\hline $20-25$ & 45 & 19.7 & 0 & 0.0 & 44 & 23.6 & \multirow[t]{4}{*}{0.001} \\
\hline $25-30$ & 108 & 47.7 & 14 & 36.4 & 94 & 50.0 & \\
\hline $30-35$ & 51 & 22.7 & 17 & 45.5 & 34 & 18.2 & \\
\hline $35-40$ & 22 & 9.8 & $4(7)$ & 18.2 & 16 & 8.2 & \\
\hline \multicolumn{8}{|l|}{ Education, n (\%) } \\
\hline Primary & 41 & 18.2 & 5 & 13.6 & 36 & 19.2 & \multirow[t]{3}{*}{0.90} \\
\hline Secondary & 125 & 55.3 & 23 & 59.1 & 102 & 54.5 & \\
\hline Tertiary & 60 & 26.5 & 10 & 27.3 & 50 & 26.4 & \\
\hline Age at menarche, mean (SD) & 14.6 & 1.7 & 14.0 & 1.8 & 14.7 & 1.6 & 0.11 \\
\hline Oral contraceptive use, n (\%) & 45 & 19.7 & 8.63 & 22.7 & 36 & 19.1 & 0.77 \\
\hline Gravidity, mean (SD) & 2.7 & 1.6 & 2.3 & 1.7 & 2.8 & 1.5 & 0.17 \\
\hline \multicolumn{8}{|l|}{ Gravidity, n (\%) } \\
\hline 1 & 57 & 25.0 & 19 & 50.0 & 38 & 20.0 & \multirow[t]{4}{*}{0.02} \\
\hline 2 & 57 & 25.0 & 3 & 9.1 & 53 & 28.2 & \\
\hline $3-4$ & 87 & 38.6 & 14 & 36.4 & 73 & 39.1 & \\
\hline$\geq 5$ & 25 & 11.4 & 2 & 4.5 & 24 & 12.7 & \\
\hline \multicolumn{8}{|l|}{ Body mass index $\left(\mathrm{kg} / \mathrm{m}^{2}\right), \mathrm{n}(\%)$} \\
\hline$<25$ & 48 & 21.2 & 7 & 18.2 & 41 & 21.8 & \multirow[t]{4}{*}{0.50} \\
\hline $25-30$ & 51 & 22.7 & 12 & 31.8 & 39 & 20.9 & \\
\hline $30-34$ & 106 & 47.0 & 14 & 36.4 & 92 & 49.1 & \\
\hline$>35$ & 21 & 9.1 & 5 & 13.6 & 16 & 8.2 & \\
\hline
\end{tabular}

$\%:$ Percentage

$S D$ standard deviation

Table 2 Clinical features of uterine fibroids among respondents with fibroids

\begin{tabular}{lll}
\hline Variables & No. of patient $(\mathbf{N}=\mathbf{3 8})$ & Frequency $\mathbf{( \% )}$ \\
\hline $\begin{array}{l}\text { Size of largest fibroid } \\
\text { (cm), mean (SD) }\end{array}$ & $2.82 \pm 1.64$ & 1.8 \\
$\begin{array}{l}\text { Feeling of a mass } \\
\text { Type of fibroid }\end{array}$ & 16 & 40.9 \\
Intramural & 5 & \\
Submucous & 9 & 13.6 \\
Subserous & 24 & 22.7 \\
Location of fibroid & & 63.7 \\
Cervix & 2 & \\
Fundus & 29 & 4.5 \\
Tubes & 2 & 77.3 \\
Pedunculated & 5 & 4.5 \\
Number of fibroids & & 13.6 \\
1 & 9 & \\
$2-3$ & 19 & 22.7 \\
$>3$ & 10 & 27.3 \\
\hline
\end{tabular}

$S D$ standard deviation $\mathrm{p}=0.008$ ), low 5 min Apgar score, (OR 6.0; 95\% CI $1.9-19.1, \mathrm{p}=0.002)$, and primary postpartum hemorrhage (OR 4.7; 95\% CI 1.7-13.2, $\mathrm{p}=0.003$ ) were adverse outcomes associated with uterine fibroids in pregnancy (Table 3).

\section{Discussion}

We determined the prevalence, clinical presentation and maternal and foetal outcomes of birth among pregnant women with leiomyoma in two secondary care hospitals in Limbe and Buea, Cameroon.

The prevalence of uterine fibroids in pregnancy was $16.7 \%$. Increasing age $(p=0.0001)$ and low parity $(\mathrm{p}=0.02)$ were associated with uterine fibroids in pregnancy. Feeling of pelvic mass $(\mathrm{p}=0.05)$, acute abdominal pain $(\mathrm{p}=0.005)$, vaginal bleeding $(\mathrm{p}=0.002)$ were clinical features associated with uterine fibroids in late pregnancy.

Adverse maternal and foetal outcomes recorded were low 5-min Apgar scores, increased caesarean birth rates and primary post-partum haemorrhage. 
Table 3 Uterine fibroids in pregnancy and outcomes

\begin{tabular}{|c|c|c|c|c|c|c|c|}
\hline \multirow[t]{2}{*}{ Outcomes } & \multicolumn{4}{|l|}{ Fibroids } & \multirow[t]{2}{*}{ OR } & \multirow[t]{2}{*}{$95 \% \mathrm{Cl}$} & \multirow[t]{2}{*}{ p-value } \\
\hline & Yes $(N=38)$ & Percentage \% & No $(N=188)$ & Percentage \% & & & \\
\hline Acute abdominal pain, n (\%) & 17 & 45.5 & 34 & 18.2 & 3.8 & $1.4-9.9$ & 0.007 \\
\hline Vaginal bleeding, n (\%) & 12 & 31.8 & 15 & 8.2 & 5.2 & $1.6-16.3$ & 0.004 \\
\hline Miscarriage, n (\%) & 14 & 36.4 & 62 & 32.7 & 1.2 & $1.6-16.3$ & 0.74 \\
\hline Delivery before 37 weeks, n (\%) & 5 & 13.6 & 17 & 9.1 & 1.6 & $03-5.7$ & 0.51 \\
\hline Cesarean delivery $(\mathrm{N}=128), \mathrm{n}(\%)$ & 12 & 31.8 & 18 & 9.4 & 4.5 & $1.4-13.6$ & 0.008 \\
\hline Baby weight <2500 g, n (\%) & 5 & 13.6 & 9 & 4.5 & 3.3 & $0.6-14.7$ & 0.12 \\
\hline 5 min Apgar score $\leq 7, \mathrm{n}(\%)$ & 12 & 31.8 & 14 & 7.3 & 6.0 & $1.9-19.1$ & 0.002 \\
\hline Blood loss at delivery > 500 mL, n (\%) & 16 & 40.9 & 24 & 12.7 & 4.7 & $1.7-13.2$ & 0.003 \\
\hline
\end{tabular}

$\%$ : Percentage

OR odds ratios, $\mathrm{Cl}$ confidence interval

\section{Prevalence of uterine fibroids in pregnancy}

The association of uterine fibroids and pregnancy has been reported in some African studies; Benin (12.5\%) and Nigeria $(12.3 \%)$, respectively $[3,9]$ and $0.87 \%$ was reported in Pakistan [10]. However, the prevalence reported in those studies was lower than the $16.7 \%$ found in our study. Our results are similar to those reported from two studies among African American women; $14.7 \%$ and $18 \%[2,11]$. These higher estimates are more compatible with those required to reach the prevalence documented in imaging studies of older non-pregnant women. It is worth noting that there is a lower incidence of leiomyoma's detected by ultrasonography during pregnancy [12] and this varies according to the trimester of assessment and size threshold [13, 14]. Therefore, obstetricians should screen for leiomyoma early in pregnancy among Cameroonian (black race) because they are at risk of having fibroids than the white race. This is linked to the high levels of oestrogen receptors ER- $\alpha$ PP genotype found in black women as compared to white women [15].

\section{General characteristics of respondents}

The association of increasing frequency of uterine fibroids in pregnancy with advancing maternal age has been reported in other African studies [4, 9]. The reason for this association may be because women in Cameroon nowadays delay childbearing for educational and career purposes. Furthermore, all the respondents were of the black race and therefore, form a high-risk group for uterine fibroids.

The respondents in this study were mainly primiparous. The average household size in Cameroon has reduced from 6.0 persons per household in the 1960's to about 5.2 per household in recent times and there are 3.2 children per household on the average $[16,17]$. However, this low parity could not be attributed to the presence of uterine fibroids alone but to other co-morbidities like sexually transmitted infections, which are frequent in Cameroon $[2,4,9]$. The protective effect of multiparity on uterine leiomyoma has been reported previously. This was confirmed in our study and it has been postulated that this protective effect occurs during uterine involution where there is remodeling of the uterine smooth muscle [18].

\section{Clinical features of fibroids in pregnancy and outcomes}

The presence of pressure symptoms, abdominal pain and vaginal bleeding during pregnancy in our study is consistent with other studies that reported symptoms, like sensation of abdominal heaviness, and pressure symptoms (increased urine frequency), lower abdominal pain and vaginal bleeding during pregnancy [19-21]. Another study carried out in five countries in Europe reported that uterine fibroids were associated with impairment of health related quality of life [20]. Muran et al. have classified uterine fibroids according to types [8]. However, we found mainly sub serous (63.5\%) and fundal (77.3\%) leiomyoma's in this study, which may create pressure symptoms; but pain is usually associated with ischemia due to growth of some fibroids during pregnancy and poor blood supply to the growing fibroid [20]. Vaginal bleeding has been reportedly associated with sub mucous fibroids or insertion of the placenta near a fibroid and may have an adverse impact on fertility $[4,9,11,18,19]$. Earlier studies have reported abruption placentae (57\%), significant pain requiring narcotic analgesia $(15.1 \%)$, preterm labor $(21.5 \%)$ and increased rates of cesarean section among pregnant women with uterine fibroids $[4,9$, 22-25]. This is consistent with our study that found low 5 min Apgar scores, increased rates of cesarean births and increased rates of primary post-partum hemorrhage. Therefore, obstetricians should be equipped for emergency cesarean birth, anticipate active management of 
third stage of labour on parturients with leiomyoma and be ready for resuscitation of the newborn.

\section{Conclusion}

One in every six pregnant women had uterine leiomyoma that presented as a sensation of pelvic heaviness, lower abdominal pain and vaginal bleeding. The adverse maternal and fetal outcomes noted were low 5-min Apgar scores, increased rates of cesarean births and primary post-partum hemorrhage.

\section{Limitations}

This paper provides supportive data on the local prevalence of fibroids in pregnancy but we could not draw any conclusions about the profile of fibroids or maternal or foetal outcomes because the numbers are too small. We did not assess the clinical experience of the sonographers for homogeneity before onset of study; since scan results were from different sonographers. We did not modify the criteria for diagnosis of uterine fibroid in pregnancy as in other studies; otherwise the prevalence may have been higher.

\section{Additional files}

\section{Additional file 1: Figure S1. Flow diagram.}

Additional file 2: Figure S2. Exteriorized uterus with multiple uterine leiomyoma's after extraction of fetus at Cesarean birth.

Additional file 3: Figure S3. Posterior view of exteriorized uterus with multiple uterine fibroids.

\section{Abbreviations}

BMI: body mass index; BRH: Buea Regional Hospital; EmONC: Emergency Obstetric and Neonatal Care; LRH: Limbe Regional Hospital; OR: odd ratio; SD: standard deviation; USB: Universal Serial Bus.

\section{Authors' contributions}

TOE and NNM did the conception, design, drafted and revised the manuscript critically for important intellectual content. BTG, RT and ENE did the data collection, analysis and interpretation. All authors read and approved the final manuscript.

\section{Author details \\ ${ }^{1}$ Department of Obstetrics and Gynaecology, Douala General Hospital, P.O. Box 4856, Douala, Cameroon. ${ }^{2}$ Faculty of Health Sciences, University of Buea, P.O.Box 63, Buea, Cameroon. ${ }^{3}$ Faculty of Medicine and Biomedical Sciences, University of Yaoundé 1, Yaoundé, Cameroon. ${ }^{4}$ Department of Obstetrics and Gynaecology, Faculty of Health Sciences, University of Buea, Buea, Cam- eroon. ${ }^{5}$ District Hospital Konye, South West Region, Konye, Cameroon.}

\section{Acknowledgements}

We thank the midwives, nurses and staff of the two hospitals for the collaboration and assistance they gave us during the study.

\section{Competing interests}

The authors declare that they have no competing interests.

\section{Availability of data and materials}

The datasets used and/or analysed during the current study are available from the corresponding author on reasonable request.

\section{Consent to publish}

Not applicable.

\section{Ethics approval and consent to participate}

Ethical clearance was obtained from the Institutional Review Board of the Faculty of Health Sciences, University of Buea and authorization was obtained from the Regional Delegation of Health, SWR and the Directors-General of the two Hospitals and written informed consent was obtained from study participants.

\section{Funding}

None.

\section{Publisher's Note}

Springer Nature remains neutral with regard to jurisdictional claims in published maps and institutional affiliations.

Received: 13 October 2018 Accepted: 10 December 2018

Published online: 13 December 2018

\section{References}

1. Kjerulff KH, Langenberg P, Seidnan JD, Stolley PD, Gazinski GM. Uterine leiomyomas. Racial differences in severity, symptoms and age at diagnosis. J Reprod Med. 1996;41:483-90.

2. Laughlin SK, Baird DD, Savitz DA, Herring AH, Hartmann KE. Prevalence of uterine leiomyomas in the first trimester of pregnancy: an ultrasound screening study. Obstet Gynecol. 2009;113:630-5.

3. Adisso S, Hounsossou H, Alle IR, Adisso EL, Takpara L, Alihonou E. Quelle issue pour la grossesse jeun dans un uterus myomateux? JBC. 2014;21:13-7.

4. Tchente NC, Fogaing AD, Tejiokem MC, Nana NP, Mbu R, Leke R. Pregnancy outcome in a group of Cameroonian women with uterine fibroids. J Gynecol Obstet Biol Reprod. 2009;38:493-9.

5. Egbe TO, Omeichu A, Halle-Ekane GE, Tchente CN, Egbe E-N, Oury J-F. Prevalence and outcome of teenage hospital births at the Buea health district, South West Region, Cameroon. Reprod Health. 2015;12:1.

6. Egbe TO, Kadzem LN, Takang WA, Tchounzou R, Egbe EN, et al. Prevalence and Risk Factors of Perineal Tears at the Limbe Regional Hospital, Cameroon. Int J Reprod Fertil Sex Health. 2016;3:70-8.

7. Eng J. Sample size estimation: how many individuals should be studied? Radiology. 2003;227:309-13.

8. Muram D, Gillieson M, Walters JH. Myomas of the uterus in pregnancy: ultrasonographic follow-up. Am J Obstet Gynecol. 1980;138:16-9.

9. Eze CU, Odumeru EA, Ochie K, Nwadike UI, Agwuna KK. Sonographic assessment of pregnancy co-existing with uterine leiomyoma in Owerri, Nigeria. Afr Health Sci. 2013;13:453-60.

10. Noor S, Fawwad A, Sultana R, Jalil H, Suleman N, Khan A. Pregnancy with fibroids and its obstetric complication. J Ayub Med Coll Abbottabad. 2009;21(4):37-40.

11. Benson CB, Chow JS, Chang-Lee W, Hill JA, Doubilet PM. Outcome of pregnancies in women with uterine leiomyomas identified by sonography in the first trimester. J Clin Ultrasound. 2001;29:261-4.

12. Laughlin SK, Herring AH, Savitz DA, Olshan AF, Fielding JR, Hartmann KE, et al. Pregnancy-related fibroid reduction. Fertil Steril. 2010;94:2421-3.

13. Cooper NP, Okolo S. Fibroids in pregnancy_common but poorly understood. Obstet Gynecol Surv. 2005;60:132-8.

14. Lee HJ, Norwitz ER, Shaw J. Contemporary management of fibroids in pregnancy. Rev Obstet Gynecol. 2010;3:20-7.

15. Al-Hendy A, Salama SA. Ethnic distribution of estrogen receptor-a polymorphism is associated with a higher prevalence of uterine leiomyomas in black Americans. Fertil Steril. 2006;86:686-93. 
16. United Nations Department of Economic and Social Affairs, Population Division (2017). Household size and Composition around the World 2017Data Booklet (ST/ESA/SER-A/405) Page 13.

17. Average household size cameroon. http://ww2.unhabitat.org/habrdd/ conditions/midafrica/cameroon.htm.

18. Baird DD, Dunson DB. Why is parity protective for uterine fibroids? Epidemiology. 2003;14:247-50.

19. Practice Committee of the American Society for Reproductive Medicine Myomas and reproductive function. Fertil Steril. 2006:86:S194-9.

20. Downes E, Sikirica V, Gilabert-Estelles J, Bolge SC, Dodd SL, Maroulis C, et al. The burden of uterine fibroids in five European countries. Eur Obstet Gynecol Reprod Biol. 2010;152:96-102

21. Conti N, Tosti C, Pinzauti S, Tomaiuolo T, Cevenini G, Severi FM, et al. Uterine fibroids affect pregnancy outcome in women over 30 years old: role of other risk factors. J Matern Fetal Neonatal Med. 2013;26:584-7.
22. Rice JP, Kay HH, Mahony BS. The clinical significance of uterine leiomyomas in pregnancy. Am J Obstet Gynecol. 1989;160:1212-6.

23. Saravelos SH, Yan J, Rehmani H, Li T-C. The prevalence and impact of fibroids and their treatment on the outcome of pregnancy in women with recurrent miscarriage. Hum Reprod. 2011;26:3274-9.

24. Lai J, Caughey AB, Qidwai Gl, Jacoby AF. Neonatal outcomes in women with sonographically identified uterine leiomyomata. J Matern Fetal Neonatal Med. 2012;25:710-3.

25. Ezeama CO, Ikechebelu J, Obiechina NJ, Ezeama NN. Clinical presentation of uterine fibroids in Nnewi, Nigeria: a 5-year review. Ann Med Health Sci Res. 2012;2:114-8.
Ready to submit your research? Choose BMC and benefit from:

- fast, convenient online submission

- thorough peer review by experienced researchers in your field

- rapid publication on acceptance

- support for research data, including large and complex data types

- gold Open Access which fosters wider collaboration and increased citations

- maximum visibility for your research: over $100 \mathrm{M}$ website views per year

At BMC, research is always in progress.

Learn more biomedcentral.com/submissions 